M. Maurizi · G. Paludetti · J. Galli · F. Ottaviani

G. D'Abramo · G. Almadori

\title{
Oncological and functional outcome of conservative surgery for primary supraglottic cancer
}

Received: 26 September 1998 / Accepted: 22 February 1999

\begin{abstract}
The aim of this study was to verify the oncological and functional outcome of conservative surgical treatment of primary supraglottic squamous cell carcinoma (SGSCC) and related neck disease in order to verify the effectiveness of supraglottic laryngectomy (SL) and the validity of an "observation" policy in the control of clinically negative (N0) necks. Of a total of 252 consecutive patients affected by primary SGSCC seen between 1975 and 1990 at the Department of Otolaryngology of the University of Perugia (1975-1987) and the Catholic University of the Sacred Heart of Rome (1988-1990), a subset of 132 patients treated with classical SL was evaluated after presenting sufficient clinicopathological data and a follow-up period of at least 5 years. Tumors were staged according to the 1992 UICC TNM classification and grouped into stages I-II $(n=94)$ and III-IV $(n=38)$. Comprehensive neck dissections were performed only in the clinically positive $(\mathrm{N}+)$ necks $(25 / 132$ cases), while in the clinically NO ones (107/132 cases) an "observation" policy under strict follow-up conditions was adopted. After primary surgery, the 5-year relapse-free survival (RFS) was $74 \%$. The RFS was $80 \%$ for T1-2 disease and $65 \%$ for T3. The RFS was $80 \%$ for stages I-II tumors and $71 \%$ for stages III-IV. The actual 5-year overall survival (OS) was $89 \%$ for T1-T2 tumors and $67 \%$ for T3 disease or $93 \%$ for stages I-II and $69 \%$ for stages III-IV. The OS was $89 \%$ for N0 neck and $73 \%$ for N+. The 5-year-metastasisfree survival (MFS) was $83 \%$ for N0 patients, $74 \%$ for $\mathrm{N}+, 84 \%$ for $\mathrm{T} 1-\mathrm{T} 2 \mathrm{~N} 0,71 \%$ for $\mathrm{T} 1-\mathrm{T} 2 \mathrm{~N}+, 81 \%$ for T3 $\mathrm{NO}$ and $68 \%$ for T3 N+. In all, SL was found to be highly effective in the management of primary SGSCC. In the
\end{abstract}

M. Maurizi (四) · G. Paludetti · J. Galli · F. Ottaviani G. Almadori

Institute of Otolaryngology, Head and Neck Surgery, Catholic University of the Sacred Heart,

Largo Agostino Gemelli 8, I-00168, Rome, Italy

G. D'Abramo

Institute of Medical Physics,

Catholic University of the Sacred Heart, Rome, Italy presence of clinically N0 neck "observation" under strict follow-up with therapeutic comprehensive neck dissection for delayed nodal recurrence, SL was suitable for controlling the neck cancer, as well as for salvaging recurrent disease. Bilateral elective, selective or functional neck dissection in every instance of supraglottic cancer was best performed only in those SGSCC patients who were more likely to have occult nodal disease on the basis of biological factors and imaging data.

Key words Supraglottic carcinoma Supraglottic laryngectomy $\cdot$ Lymph-node metastases $\cdot$ Neck treatment Prognosis

\section{Introduction}

Cancer of the larynx accounts for $2 \%$ of the total cancer risk and represents the second-most-common head and neck cancer. The American Cancer Society estimated approximately 12,000 new cases of laryngeal cancer in the United States in 1995 [4]. Eighty-eight to $96 \%$ of the total laryngeal cancers consist of squamous cell carcinomas (SCC) $[4,15,42]$, with the ratio of glottic to supraglottic SCC being approximately $2: 1$ [42].

Despite recent advances in all areas of diagnosis and treatment, the outcome of patients with supraglottic laryngeal SCC (SLSCC) has reached a plateau in the last 2 decades. Also, the slight but definite increase in advanced-staged disease indicates that efforts toward early detection have not been successful [42]. The primary goal of the treatment of SLSCC is clearly initial cancer control (i.e., local, regional and distant control, as well as the salvageability of recurrent disease and the prevention of second primary tumors) and overall and disease-free survival. However, according to current concepts of function or organ preservation, new parameters for the success of treatment such as quality of life, quality of preserved function and cost-effectiveness are now desirable secondary goals.

Prognosis is determined by age, performance status, tumor location and size, lymph-node involvement and 
stage of disease. More particularly, node-positive necks have a decisive influence on prognosis in patients with SGSSC where local recurrences are rarely observed [36, 44]. In fact, regrouping stage III and IV cases into localizad disease versus regional metastasis appears to predict survival better [42].

The choice of initial treatment of the SGSCC depends on patient, tumor and physician factors [31,39]. The standard options of treatment are conservative surgery, radiotherapy and/or chemotherapy $[6,31]$. In addition to this, early lesions can be managed by endoscopic supraglottic laryngectomy (SL) using the $\mathrm{CO}_{2}$ laser, with respectable control rates [27, 32, 55]. Most importantly, SL is a wellestablished voice-sparing operation for the treatment of supraglottic tumors that was first described and codified by Alonso [2] in 1947 and subsequently has been modified by Alonso [3], Bocca [5, 6], Leroux-Robert [20, 21], Ogura [33, 34] and Tapia [49]. For embryological, anatomical and oncological reasons, conservative SL produces survival rates that are virtually the same as for total laryngectomy, consistently ranging from approximately 68 to $90 \%[6,8,37]$. It is now widely accepted that early-stage SGSCC can be adequately treated with single-modality therapy, using either conservative surgery or irradiation, while advanced tumors require surgery combined with radiotherapy and/or chemotherapy, as well as possibly salvage surgery [48].

Conservative surgery is indicated as initial therapy for $\mathrm{T} 1$ and $\mathrm{T} 2$ lesions in patients with N0 or N1 neck disease and is also recommended for primary tumors with extension to the base of the tongue or the hypopharynx [25, 26, 45], as well as in large, bulky, infiltrative lesions, and in cases with extensive pre-epiglottic space involvement [42].

In addition to treatment of the primary tumor, the management of cervical lymph nodes also represents an important component of the overall treatment strategy. While comprehensive neck dissection is widely reported as mandatory during initial treatment in cases with clinically positive neck nodes, no consensus exists on whether or not an elective neck dissection should be performed in SLSCC patients with clinically negative neck. Management of the NO neck includes elective, selective or functional neck dissection or elective irradiation and observation with any statistical differences in terms of survival (overall and disease free), salvageability of recurrent disease and quality of life [40]. Elective bilateral jugular neck dissections have been advocated as both a therapeutic and staging modality and are currently the most common unsettled surgical option in SLSCC patients with clinically N0 neck $[1,7,9,13,17,24,40,52,53]$. However, elective bilateral jugular neck dissections in every instance of primary SGSCC could produce overtreatment with a concomitant unnecessary increase in costs, duration of treatment and treatment-related morbidity $[18,35]$. On the other hand, the effectiveness of observation alone still remains unproved [47]. As the treatment of laryngeal SCC has undergone an evolution and significant progress has been made in initial cancer control as well as in the quality of life, increasing emphasis on improved function and cosmesis is now also evident in the management of the neck [14]. The evolution of the neck dissection from Crile's radical operation through modified radical, functional and comprehensive neck dissections and selective neck dissections $[7,10,38,40]$ is representative of this trend.

This report is an update on the oncological and functional outcomes of cancer-directed primary conservative surgery as the initial single treatment of SGSCC patients in the Department of Otolaryngology of the University of Perugia (1975-1987) and at Catholic University of the Sacred Heart, Rome (1988-1990). Furthermore, the effectiveness of observation in the control of clinically N0 necks was also evaluated.

\section{Patients and methods}

In all, the results of treatment of 252 consecutive patients managed by primary supraglottic SCC were reviewed. All patients were seen from 1975 through 1990 at the Departments of Otorhinolaryngology of the University of Perugia (1975-1987) and the Catholic University of the Sacred Heart of Rome (1988-1990). Twenty-two of the patients underwent exclusive radiotherapy and 26 cases total laryngectomy because of advanced age, poor pulmonary reserve, and other related factors (occupation, preference, and ability to comply with the prescribed treatment program) were not suitable for conservative surgery. These cases were excluded from this study. Because of an inappropriate anatomic site code or an unknown or incomplete post-operative follow-up, 41 other cases were also omitted, leaving 163 cases for review. Thirty-one patients had tumors also involving the base of the tongue and the hypopharynx and underwent an extended SL. This group will be evaluated in a separate publication. The remaining 132 cases had classical SL as initial treatment, presented sufficient clinicopathological data and follow-up of at least 5 years and were suitable for the present statistical analysis.

Tumors were staged according to the 1992 UICC TNM classification [50] as follows: T1N0 $(n=28)$, T1N1 $(n=7)$, T1N2 $(n=$ $2)$, T2N0 $(n=66)$, T2N1 $(n=7)$, T2N2 $(n=3)$, T3N0 $(n=12)$, T3N1 $(n=2)$ and T3N2 $(n=5)$. All cases were grouped as stage III (94 patients) and stage III-IV (38 patients). Tumors were also graded as well differentiated (G1, 30 patients), moderately differentiated (G2, 52 patients) and poorly differentiated (G3, 50 patients). Age, TNM classification, histopathological grading, early and late complications, 5-year relapse-free survival (RFS), 5-year metastasis-free survival (MFS) and 5-year overall survival (OS) were recorded and a statistical analysis performed.

All primary SGSCC patients received conservative curative surgery (supraglottic laryngectomy) of the primary tumor and comprehensive neck dissection only in clinically positive necks (stage $\mathrm{N}+; 25$ cases), while in the clinically negative neck (stage NO; 107 cases) there was a wait-and-see or observation policy under strict follow-up conditions. Delayed comprehensive neck dissection was performed only when the originally clinically NO neck nodes had become clinically positive ( 21 cases).

Postoperative radiotherapy to $50-70$ Gy was used after primary conservative surgery in 14 out of the 25 SGSCC patients with clinically positive necks, cases with extracapsular spread (5 patients) and in cases with multiple or greater than N1 stage nodal disease (9 patients).

Statistical analysis was performed by means of a statistical package (rel. 4.5). All survival curves were examined by means of the log-rank test [23] grouping by $\mathrm{T}$ classification (T1-2 vs T3), lymph-node involvement (NO vs N+), histopathological grading (G1-2 vs G3) and stage (I-II vs III-IV). Five-year RFS and MFS were calculated from the date of primary surgery to the date of local and regional clinical and pathological recurrence of disease, re- 
spectively. Five-year actual OS was calculated from the date of first surgery to the date of death from disease (DOD).

\section{Results}

Case-mix characteristics

Clinicopathological characteristics and univariate analysis of prognostic variable for survival in the 132 primary SGSCC patients are shown in Table 1. The majority of SGSCC patients presented with early-stage disease (94/132), clinically negative neck disease (106/132) and G1-G2 differentiated tumors (82/132). T classification and stage of disease showed a significant correlation with
RFS ( $P=0.005$ and $P=0.03$, respectively), and shorter OS ( $P=005$ and $P=0.0002$, respectively), while no significant relationships were found between MFS and the other prognostic factors evaluated. Age only significantly correlated with shorter OS $(P=0.05)$.

\section{Relapse-free survival}

The 5-year RFS was 74\%, with the residual larynx being the most frequent site of recurence (Figs.1,2). The 5-year RFS according to $\mathrm{T}$ stage was $80 \%$ for $\mathrm{T} 1-2$ tumors and $65 \%$ for $\mathrm{T} 3$ disease, while the RFS according to stage was $80 \%$ for stages I-II and $71 \%$ for stages III-IV. Thirty-four patients underwent total laryngectomy for local tumor re-

Table 1 Univariate analysis of prognostic variables for survival in 132 primary laryngeal cancer patients

\begin{tabular}{|c|c|c|c|c|c|c|c|c|c|c|}
\hline Prognostic variable & No. & \multicolumn{3}{|c|}{ Overall survival } & \multicolumn{3}{|c|}{ Relapse-free survival } & \multicolumn{3}{|c|}{ Metastasis-free survival } \\
\hline \multicolumn{11}{|l|}{ Age } \\
\hline$<60$ & 63 & 91 & 1 & & 82 & 1 & & 85 & 1 & \\
\hline $1-2$ & 113 & 89 & 1 & & 80 & 1 & & 81 & 1 & \\
\hline $3-4$ & 19 & 67 & 3.2 & 0.005 & 55 & 2.4 & 0.005 & 83 & 0.9 & 0.5 \\
\hline \multicolumn{11}{|c|}{ Lymph-node involvement } \\
\hline No & 107 & 89 & 1 & & 79 & 1 & & - & 1 & \\
\hline Yes & 25 & 73 & 2.3 & 0.03 & 65 & 1.5 & 0.1 & - & 0.4 & n.a. \\
\hline \multicolumn{11}{|l|}{ Stage } \\
\hline $\mathrm{I}-\mathrm{II}$ & 94 & 83 & 1 & & 80 & 1 & & 81 & 1 & \\
\hline III-IV & 38 & 69 & 4.5 & 0.0002 & 67 & 1.8 & 0.03 & 83 & 0.9 & 0.5 \\
\hline
\end{tabular}

${ }^{a} \mathrm{RR}$ relative risk corresponds to the number of adverse events in one category expressed as a proportion of reference-category events

Fig. 1 Five-year RFS according to $\mathrm{T}$ classification in 132 laryngeal cancer patients
Relapse Free Survival

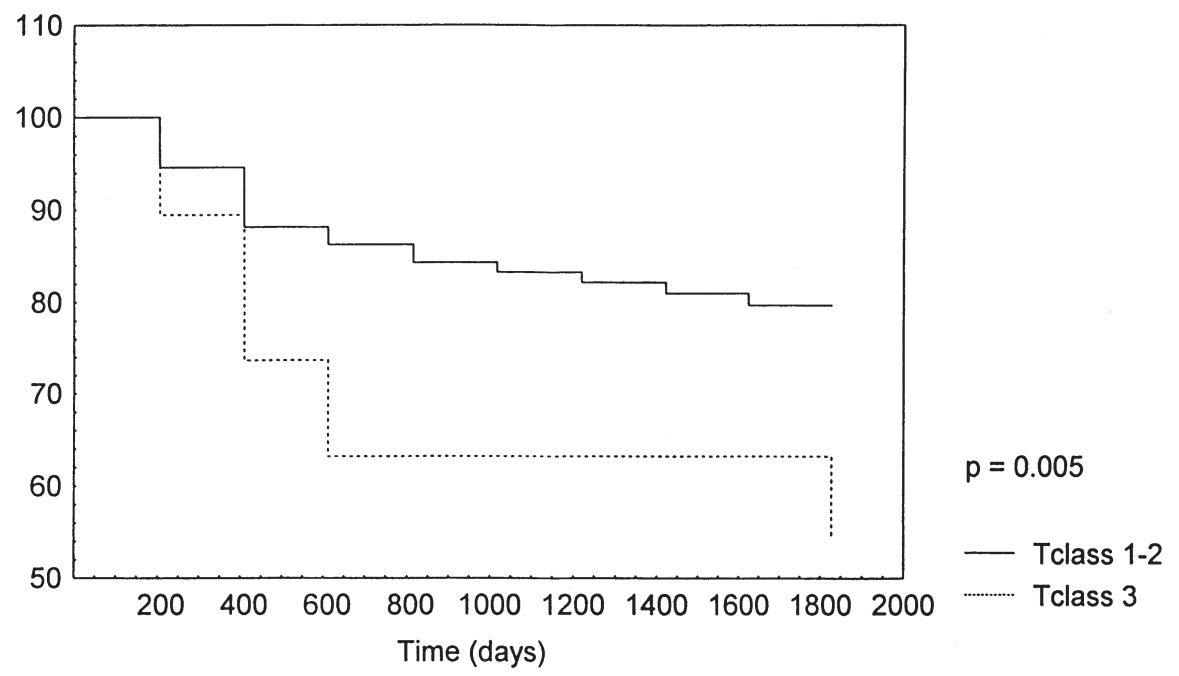


Fig. 2 Five-year RFS according to stage in 132 laryngeal cancer patients

Fig.3 The actual 5-year OS for all 132 primary laryngeal cancer patients

Fig.4 The actual 5-year OS according to $\mathrm{T}$ classification in 132 primary laryngeal cancer patients
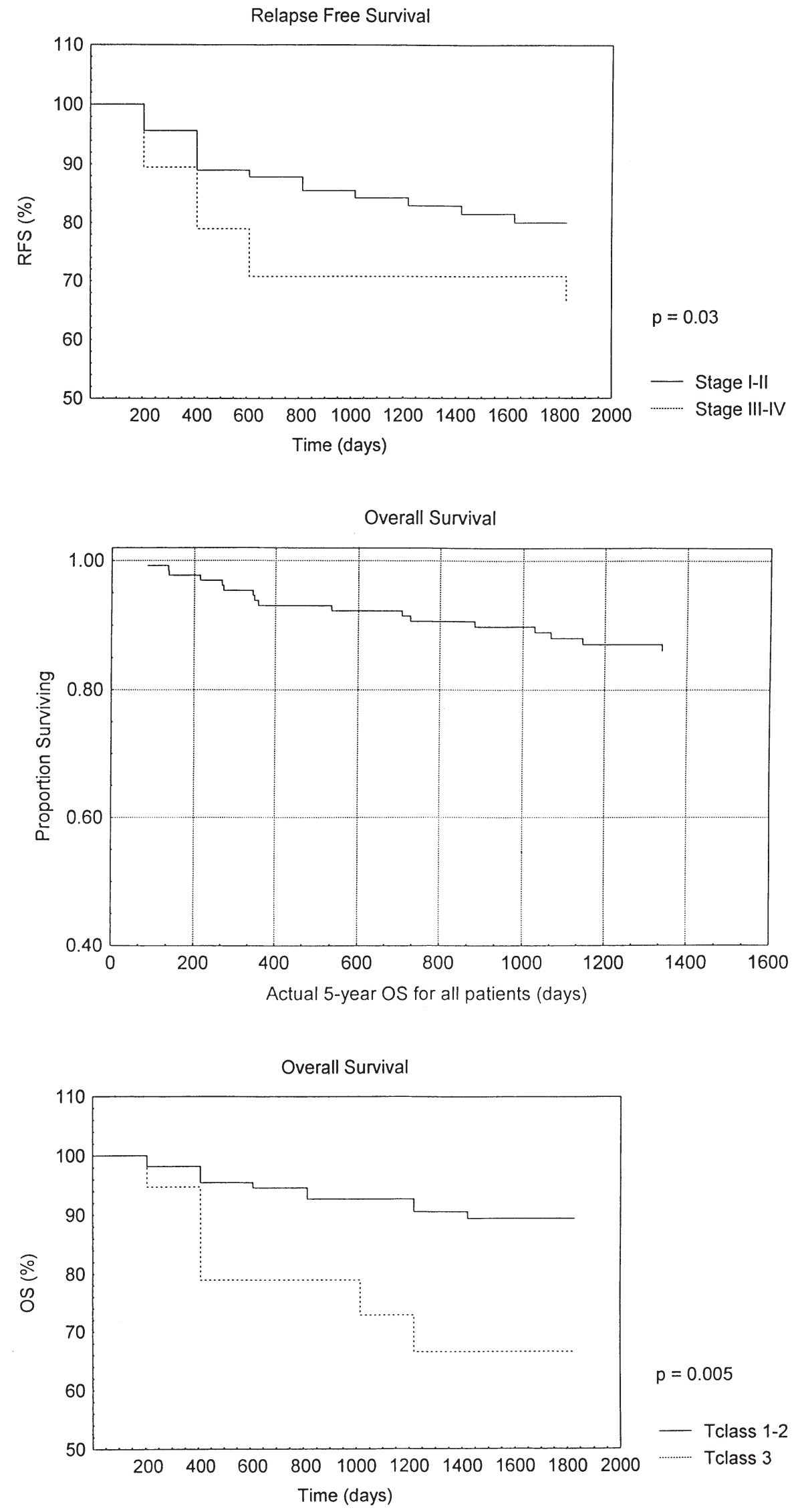
Fig.5 The actual 5-year OS according to stage in 132 primary laryngeal cancer patients
Fig.6 The actual 5-year OS according to age in 132 primary laryngeal cancer patients
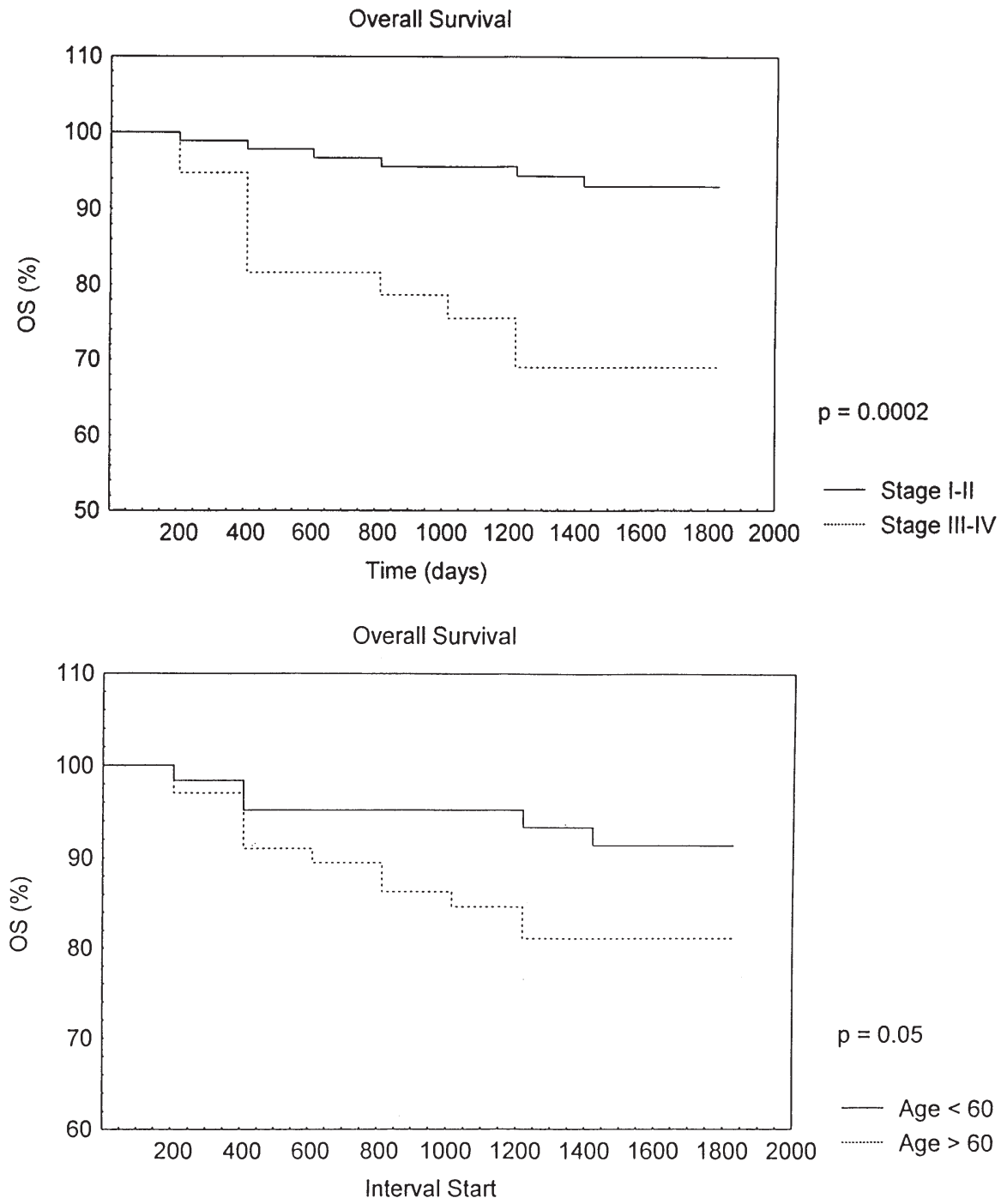

lapses (3 T1, $16 \mathrm{~T} 2$ and $15 \mathrm{~T} 3$ ): 17 are still alive without evidence of locoregional disease, while the other 17 died as the result of extralaryngeal spread.

\section{Survival}

The 5-year actual OS was $86 \%$ (Fig. 3). The OS according to $\mathrm{T}$ classification was $89 \%$ for T1-2 tumors and $67 \%$ for T3 ones (Fig. 4). This was $93 \%$ for stages I-II and $69 \%$ for stages III-IV (Fig.5), while it was $89 \%$ for clinically negative neck (stage N0) and $73 \%$ for clinically positive one (stage $\mathrm{N}+$ ). Actual 5-year OS according to age was $91 \%$ for patients under 60 years and $81 \%$ for older patients (Table 1, Fig.6).

\section{Neck recurrence}

The global 5-year MFS was 78\% (Fig.7). The MFS according to $\mathrm{N}$ stage was $80 \%(86 / 107)$ for N0 (Fig.8) and $74 \%(23 / 25)$ for $\mathrm{N}+$, while MFS according to $\mathrm{T}$ and $\mathrm{N}$ stage was $84 \%$ for $\mathrm{T} 1-\mathrm{T} 2 \mathrm{~N} 0$ and $71 \%$ for $\mathrm{T} 1-\mathrm{T} 2 \mathrm{~N}+$, and $81 \%$ for T3 N0 and $68 \%$ for T3 N+. The 5-year MFS was $85 \%$ for patients under 60 years and $77 \%$ for older patients. Of the 107 untreated patients with clinically N0 necks, 21 patients developed neck-node metastases in a period ranging from 3 to 52 months following initial primary surgery. Fourteen of them presented with delayed N1 metastatic neck disease and underwent therapeutic comprehensive neck dissections (salvage surgery) with adjuvant radiotherapy in only 2 cases ( $\mathrm{pN} 1$ with extranodal spread): all are still alive without disease. Seven patients presented delayed metastatic neck disease greater than N1 and also underwent postsurgical adjuvant irradiation (five cases) and adjuvant radiochemotherapy (2 cases): all died of disease.

Functional outcome

All patients had difficulty in swallowing. However, a feeding tube was removed between 10 and 30 days after surgery in all patients except in two who regained by-pass 
Fig.7 The global 5-year MFS in 132 primary laryngeal cancer patients

Fig. 8 The MFS according to N0 stage in 132 primary laryngeal cancer patients
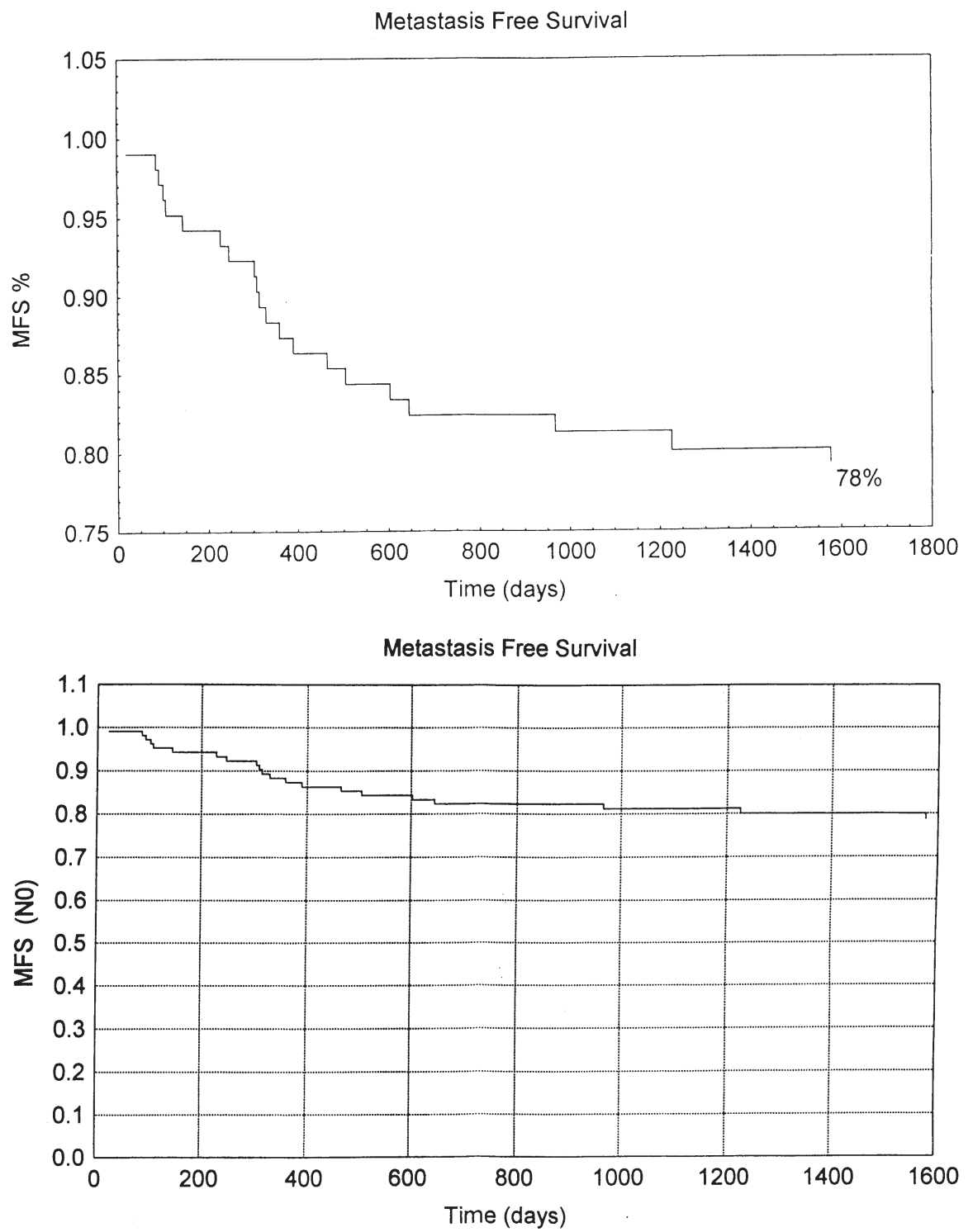

feeding for about 60 days after primary surgery. Immediate postoperative complications were local infection (ten patients) and pharyngocutaneous fistulas (eight patients). Minor postoperative hemorrhages occurred in five. Decannulation was possible in 120/132 of the patients over a period ranging from 2 to 6 months. Twelve patients (9\%) were not decannulated, four because of laryngeal stenosis and five because of mucosal flaps. In these latter cases endoscopic $\mathrm{CO}_{2}$ laser surgery was performed. Two patients preferred to retain their tracheostomy tubes. One patient underwent total laryngectomy because of persistent aspiration.

\section{Discussion}

In our series the 5-year actual OS of $86 \%$ was comparable to that reported in other surgical series, ranging from approximately 68 to $90 \%$ and depending mainly on the duration of follow-up $[6,8,29,37]$. Conservative SL as ini- tial surgery was highly curative in the management of our SGSCC patients and did as well as total laryngectomy if the indication for surgery was properly established. Also, our 5-year RFS rate of 74\% is comparable to data on local recurrence rates reported in the literature, ranging from approximately 1 to $30 \%[22,34,37,46]$. On univariate analysis, $T$ classification and clinical stage of the disease were significant independent prognostic factors for both OS and RFS. The prognostic value of the clinical neck status was not related to OS and RFS, probably because $\mathrm{N}+$ necks were fewer than $\mathrm{N} 0$ ones.

The global 5-year MFS was 78\% and had no significant correlation with all prognostic variables considered. More particularly, the SGSCC patients with clinically NO neck supraglottic laryngectomies and observation with therapeutic neck dissection (surgical salvage) performed if neck node metastastasis became clinically apparent was considered to be an effective available option for initial locoregional cancer control as well as for salvageability of recurrent neck disease and quality of life. However, simi- 
lar to the findings by Shah [41], we observed a considerable number of patients with delayed clinically metastatic neck disease greater than N1, in whom surgical salvage failed both for survival as well as for salvageability of recurrent disease.

Although elective ipsilateral or bilateral jugular neck dissection has been advocated as both a therapeutic and staging modality, it is currently the most common unsettled surgical option in SGSCC patients where occult neck metastatic disease has been proven in about 16 to $37 \%$ of patients with no palpable nodes $[6,7,22,46]$. The management of the clinically N0 neck is still controversial.

In fact, it is not possible to document a statistically significant difference in regional control rate and survival between patients who underwent elective neck dissection and showing occult micrometastasis and those who underwent therapeutic neck dissection for the delayed appearance of N1 disease [16, 42]. Furthermore, selective or more functional neck dissection in every instance of primary SGSCC in NO necks was felt to represent overtreatment and created unnecessary treatment-related morbidity for patients who do not have occult lymph-node metastasis (true-negative cases) $[18,19,35]$. Additionally, selective or functional neck dissection was felt to remove or destroy a barrier to cancer spread that might be particularly important if recurrence at the primary site should occur later [43].

The effectiveness of observation with surgical salvage for delayed nodal recurrence remains unproved [47]. Despite several reports about the incidence of occult cervical lymph nodes metastases in primary SGSCC, the risk in any individual patient cannot be determined absolutely. More information is needed to select those patients with clinically negative necks who are most likely to benefit from elective selective neck dissection, thus to avoid overtreatment.

Patterns of care are influenced by advances in technology that modify diagnostic capabilities and therapeutic interventions. Although the translation of these advances from research studies to clinical practice generally occurs slowly, the improvement in imaging diagnostic tools, such as magnetic resonance studies [51], positron emission tomography [56], radioimmunoscintigraphy $[11,12]$ and a better understanding of molecular biology of the primary tumor for detecting or predicting the presence of propensity of neck node metastasis $[28,30]$ might contribute to lessen the indications for elective neck dissection in the future.

Although wider multi-institutional and multidisciplinary studies are needed before more specific conclusions can be drawn, our results suggest the possibility of limiting elective (selective or functional) neck dissections to more selected SGSCC patients who are most likely to have occult nodal disease or high regional metastatic propency on the basis of imaging data and biological markers.

Concerning functional outcome, although aspiration was the most frequent postoperative complication, most of our patients were able to eat satisfactorily within 2 or
3 postoperative weeks [54]. Aspiration is probably the result of the combined effects of more than one single factor. The effects on swallowing of superior laryngeal nerve preservation, cricopharyngeal myotomy and hyoid bone sparing are yet to be proven. This kind of complication should be contemplated when selecting patients for supraglottic laryngectomy, and age and pulmonary conditions must be carefully evaluated. Another complication, which can delay decannulation, was related to airway obstruction due to arytenoid edema, mucosal flaps and/or laryngeal stenosis $[6,26]$. In these cases steroids and $\mathrm{CO}_{2}$ laser microsurgery were sometimes required.

\section{References}

1. Ali' S, Tiwari RM, Snow GB (1985) False positive and false negative neck nodes. Head Neck Surg 8:78-82

2. Alonso JM (1947) Conservative surgery of cancer of the larynx. Trans Am Acad Ophthalmol Otolaryngol 51:633-642

3. Alonso JM (1966) Horizontal partial laryngectomy. Laryngoscope $76: 61-69$

4. American Cancer Society (1995) Cancer facts and figures 1995. American Cancer Society, Atlanta

5. Bocca E, Pignataro O, Mosciaro O (1968) Supraglottic surgery of the larynx. Ann Otol Rhinol Laryngol 77: 1004-1026

6. Bocca E, Pignataro O, Oldini C (1983) Supraglottic laryngectomy: 30 years of experience. Ann Otol Rhinol Laryngol 96 : $14-18$

7. Bocca E, Calearo C, De Vincentiis I, Marullo T, Motta G, Ottaviani A (1984) Occult metastases in cancer of the larynx and their relationship to clinical and histological aspects of the primary tumor: a four-year multicentric research. Laryngoscope 94:1086-1090

8. Burstein F, Calcaterra T (1985) Supraglottic laryngectomy: series report and analysis of results. Laryngoscope 95:833-836

9.Byers RM, Wolf PF, Ballantyne AJ (1988) Rationale for elective modified neck dissection. Head Neck Surg 10:60-167

10. Crile G (1906) Excision of cancer of the head and neck. JAMA 47: $1780-1786$

11. De Bree R, Roos JC, Quack JJ, Den Hollander W, Van Den Brekel W, Van Der Wal JE, Tobi H, Snow GB, Van Dongen G AMS (1994) Clinical imaging of head and neck cancer with technetium-99m-labeled monoclonal antibody E48 IgG or F(ab')2. J Nucl Med 35:775-783

12.De Rossi G, Maurizi M, Almadori A, Di Giuda D, Paludetti G, Cadoni G, Ottaviani F, Galli J (1997) The contribution of immunoscintigraphy to the diagnosis of head and neck tumours. Nucl Med Commun 18:10-16

13. DeSanto W, Behars OH (1988) Modified and complete neck dissection in the treatment of squamous cell carcinoma of the head and neck. Surg Gynecol Obstet 167:259-269

14.Eicher SA, Weber RS (1996) Surgical management of cervical lymph-node metastases. Curr Opin Oncol 8:215-220

15.Ferlito A (1996) Surgical pathology of laryngeal neoplasms. Ferlito A (ed) Chapman and Hall Medical, London

16. Gallo O, Boddi V, Bottai G, Parrella F, Fini-Storchi O (1996) Treatment of the clinically negative neck in laryngeal cancer patients. Head Neck 18:566-572

17. Gavilan C, Gavilan J (1989) Five-year results of functional neck dissection for cancer of the larynx. Arch Otolaryngol Head Neck Surg 115:1193-1196

18. Lake GM, Di Nardo LJ, Dimeo JH (1994) Performance of the internal jugular vein after functional neck dissection. Otolaryngol Head Neck Surg 111:201-204

19.Leontsinis TG, Curne AR, Mannell A (1995) Internal jugular vein thrombosis following functional neck dissection. Laryngoscope $105:$ 169-174 
20.Leroux-Robert J (1957) La chirurgie conservatrice dans le cancer du larynx. Ann Otolaryngol 74:40-74

21.Leroux-Robert J (1969) Les possibilites d'une chirurgie conservatrice fonctionelle dans le cancer du larynx. Acta Otorhinolaryngol Belg $23: 523-549$

22. Lutz C, Johnson J, Wagner R, Myers E (1990) Supraglottic carcinoma: patterns of recurrence. Ann Otol Rhinol Laryngol 99: $12-17$

23. Mantel N (1966) Evaluation of survival data and two new rank order statistics arising in its consideration. Cancer Chemother Rep 50:163-170

24. Marks JE, Freeman RB, Lee F, Ogura JH (1979) Carcinoma of the supraglottic larynx. Am J Roentgenol 132:255-260

25. Maurizi M, Ottaviani F (1993) Le laringectomie sopraglottiche allargate. In: Chirurgia funzionale della laringe: stato dell'arte. Relaz. Uff. LXXX Congresso Naz. SIO, Udine, pp 323-332, Pacini, Pisa

26. Maurizi M, Frenguelli A, Nardi S, Rosignoli M (1975) Sequele funzionali della laringectomia sovraglottica allargata. Valsalva $51: 155-162$

27. Maurizi M, Paludetti G, Del Ninno M, Almadori G (1995) L'impiego del Laser $\mathrm{CO}_{2}$ nelle neoplasie della regione sovraglottica. Riv ItaI Otorinol Audiol Fon 4:279-284

28. Maurizi M, Almadori G, Ferrandina G, Distefano M, Romanini M, Cadoni G, Benedetti-Panici P, Paludetti G, Scambia G, Mancuso S (1996) Prognostic significance of epidermal growth factor receptor in laryngeal squamous cell carcinoma. Br $\mathrm{J}$ Cancer 74:253-1257

29.Maurizi M, Almadori G, Cadoni G, Scambia G, Ottaviani F, Ferrandina G, Paludetti G, D’Abramo G, Mancuso S (1996) Cathepsin D concentration in primary laryngeal cancer: correlation with clinico-pathological parameters, EGFR status and prognosis. Int J Cancer 69: 105-109

30. Maurizi M, Ferrandina G, Almadori G, Scambia G, Cadoni G, D'Agostino G, Serra FG, Piantelli M, Mancuso S, Ranelletti FO (1997) Prognostic significance of methyl-p-hydroxy-phenyllactate-esterase activity in laryngeal squamous cell carcinoma. Br J Cancer 77: 1260-1266

31. Million R, Cassisi N (1994) Management of head and neck cancer: a multidisciplinary approach, 2nd edn. Lippincott, Philadelphia

32. Motta G, Villari G, Esposito E, Cassiano B (1993) Chirurgia endoscopica delle neoplasie sopraglottiche. In: Chirurgia funzionale della laringe: stato dell'arte. Relaz. Uff. LXXX Congresso Naz. SIO, Udine, pp 299-314, Pacini, Pisa

33. Ogura J, Sessions D, Spector G (1975) Conservation surgery for epidermoid carcinoma of the supraglottic larynx. Laryngoscope $85: 1808-1815$

34. Ogura JH, Marks JE, Freeman RB (1980) Results of conservation surgery for cancers of the supraglottis and pyriform sinus. Laryngoscope 90:591-600

35. Quraishi HA, Wax MK, Granke K, Rodman SM (1997) Internal jugular vein thrombosis after functional and selective neck dissection. Arch Otolaryngol Head Neck Surg 123:969-973

36. Resnick MJ, Uhlman D, Niehans GA, Gapany M, Adams G, Knapp D, Jaszcz W (1995) Cervical lymph node status and survival in laryngeal carcinoma: prognostic factors. Ann Otol Rhinol Laryngol 104:685-694

37. Robbins K, Davidson W, Peters L, Goepfert H (1988) Conservation surgery for T2 and T3 carcinomas of the supraglottic larynx. Arch Otolaryngol Head Neck Surg 114:421-426
38. Robbins KT, Medina JE, Wolfe GT, Levine PA, Session RB, Pruet CW (1991) Standardizing neck dissection terminology. Arch Otolaryngol Head Neck Surg 117:601-605

39. Salimbeni C, Alajmo E, Fini Storchi O (1979) Riflessioni sulla laringectomia orizzontale sopraglottica: valutazione critica del decorso di 207 casi. Minerva Otolaringol 29:29-32

40. Shah JP (1990) Patterns of cervical lymph node metastasis from squamous carcinoma of the upper aerodigestive tract. Am J Surg 160:405-409

41. Shah JP (1996) Head and neck surgery, 2nd edn. MoshyWolfe, Barcelona

42. Shah JP, Karnell LH, Hoffman HT, Ariyan S, Brown GS, Fee WE, Glass AG, Goepfert H, Ossof RH, Fremgen A (1997) Patterns of care for cancer of larynx in the United States Arch Otolaryngol Head Neck Surg 123:475-483

43. Snow GB (1993) The NO neck in head and neck cancer patients. Eur Arch Oto-rhinolaryngol 250:423

44. Snow GB, Annyas A, Vanslooten A, Bartelink H, Hart A (1982) Prognostic factors of neck node metastases. Clin Otolaryngol 7:185-192

45. Som ML (1970) Conservation surgery for carcinoma of the supraglottis. J Laryngol Otol 4:665-678

46. Spaulding C, Constable W, Levine P, Cantrell R (1989) Partial laryngectomy and radiotherapy for supraglottic cancer: a conservative approach. Ann Otol Rhinol Laryngol 98:125-129

47. Stell PM, Morton RP, Singh SD (1983) Cervical lymph node metastasis: the significance of level of the lymph node. Clin Oncol R Coll Radiol 9: 101-107

48. Suarez C, Rodrigo J, Herranz J, llorente J, Martinez J (1995) Supraglottic laryngectomy with or without postoperative radiotherapy in supraglottic carcinomas. Ann Otol Rhinol Laryngol 104:358-369

49. Tapia R (1973) Laryngectomie horizontale susglottique par voie transthyroidienne. J F ORL 22:797-804

50. Unio Internationalis Contra Cancrum (UICC) (1992) TNM classifications of malignant tumours, 4th edn, 2nd rev. Springer, Berlin Heidelberg New York

51. Van den Brekel MWM, Castelijns JA, Croll GA, Stel HV, Valk J, Van der Waal I, Golding RP, Meyer CJLM, Snow GB (1991) Magnetic resonance imaging vs palpation of cervical lymph node metastasis. Arch Otolaryngol Head Neck Surg 117:666673

52. Weber PC, Johnson JT, Myers EN (1993) Impact of bilateral neck dissection on recovery following supraglottic laryngectomy. Arch Otolaryngol Head Neck Surg 119:61-64

53. Weber PC, Johnson JT, Myers EN (1994) The impact of bilateral neck dissection on pattern of recurrence and survival in supraglottic carcinoma. Arch Otolaryngol Head Neck Surg 120 : 703-706

54. Woisard V, Serrano E, Yardeni E, Puech M, Pessey J (1993) Deglutition after supra-glottic laryngectomy. J Otolaryngol 22: 278-283

55.Zeitel SM, Vaughan CW, Domanowski GF (1990) Endoscopic management of early supraglottic cancer. Ann Otol Rhinol Laryngol 99:951-956

56.Zeitouni AG, Yamamoto YL, Black M, Gjedde A (1994) Functional imaging of head and neck tumors using positron emission tomography. J Otolaryngol 23:77-80 